Original Research Paper

\title{
Research on Efficiency of Applying Gamified Design into University's e-Courses: 3D Modeling and Programming
}

\author{
Andrija Bernik, Danijel Radošević and Daniel Strmečki \\ Faculty of Organization and Informatics, University of Zagreb, Pavlinska 2, 42000 Varaždin, Croatia
}

\author{
Article history \\ Received: $26-07-2017$ \\ Revised: 04-11-2017 \\ Accepted: 08-12-2017 \\ Corresponding Author: \\ Danijel Radošević, \\ Faculty of Organization and \\ Informatics, University of \\ Zagreb, Pavlinska 2, 42000 \\ Varaždin, Croatia \\ Email: danijel.radosevic@foi.hr
}

\begin{abstract}
Research presented in this paper represents a further step towards proving the efficiency of gamification in higher education. Our research was conducted within two higher education institutions and includes full-time and part-time students who enrolled in the courses $3 D$ modeling and Programming. Based on the research results, three hypotheses were tested. These hypotheses give a better insight into some psychological phenomes. The first hypotheses tested the level of knowledge in experimental and control groups for all students who achieved a minimum of $50 \%$ score in the pre-test. Our results confirmed the existence of statistically significant difference in the benefit of the experimental group. The other two hypotheses are spreading results even more. We analyzed 50\% of the highest ranked and also $50 \%$ of the lowest ranked students' score with the use of t-test. Based on our analysis of the average number of points on the post-test for participants with the lowest ranking we found no statistically significant difference. On the other hand, the same analysis for participants with the highest ranking shows, with statistically significant difference, that the experimental group achieved notably better score.
\end{abstract}

Keywords: E-Learning, E-Course, Gamification, Gamified, Moodle, LMS

\section{Introduction}

Gamification for learning can be defined as usage of game-based mechanics, aesthetics and game thinking to engage people, motivate action, promote learning and solve problems (Enders, 2013; Kapp, 2012). Mechanics are the functioning components of the game, like a set of rules and feedback loops that make the game fun. Dynamics imply player's interactions with mechanics and aesthetics relate to how the game makes the player feel during those interactions (Enders, 2013; Zichermann and Cunningham, 2011). Gamification is applied in ecourses in order to increase participants' motivation, experience and engagement (Domínguez et al., 2013). It relies both on technology: E-learning systems on Web and mobile platforms; and psychology: Peoples' competition instinct and sense of pride and achievement (Glover, 2013).

The main motivation for this research is to extend the existing research results of the influence of gamification on student knowledge and their motivation with more detailed analysis. We would also like to contribute to a better understanding of gamifications impact on students in higher education in the Computer Graphic (CG) and programming fields. Through our earlier studies (Bernik et al., 2015; 2017), it was confirmed that an experimental group of participants achieved better results in post-test knowledge testes, but now we are interested in investigating how significant is the difference in results. We developed an experimental ecourse in which the results of $50 \%$ of the highest ranked students and $50 \%$ of the lowest ranked students were analyzed. The results of our research are presented in the following chapters and it shows interesting conclusions where statistical significant differences are presented.

\section{Related Work}

Gamification is a term with its origins in the digital media industry. It was widely adopted from 2010, after usage of some parallel terms, like productivity games, surveillance entertainment, funware, playful design, behavioral games, game layer or applied gaming (Deterding et al., 2011). There were many questions about the nature of the concept and its real effectiveness for the teaching process. According to Hamari et al. (2014), gamification can be seen through three main parts: The implemented motivational affordances, the resulting psychological outcomes and by the further 
behavioral outcomes. From that standpoint, the main benefit of gamification should be the increasing motivation for learning of different contents. On the other hand, games are seen as a collection of multiple necessary conditions and none of these conditions alone is sufficient to constitute a game, but only the combination of them. Such combination of conditions could be arranged on three separate abstraction levels (Huotari and Hamari, 2012). The first level simply states that games are systems, i.e., constituted of several interacting sets of mechanisms and actors and that games always require the active involvement of at least one player. The second abstraction level includes some systemic conditions as rules, conflicting goals and uncertain outcomes. The third abstraction level should include conditions that are unique to games. However, it's hard to find these specific condition for games, so Huotari and Hamari (2012; Hamari et al., 2014) suggest the adoption of term gamefulness.

There different approaches in the implementation of the concept of gamification. For example, author Brenda Enders (2013) proposes the implementation of gaming elements in e-learning like points, achievements, badges, leaderboards, levels and challenge. The author provides some guidelines for the design of gamified elearning systems, but concludes that more research on gamification elements effectiveness in e-learning systems are required. Hof et al. (2017) studied the usage gamification in acquiring competences in communication and collaboration that are necessary for applying agile software methods like Scrum. The results show that students like this approach much more than traditional ex-cathedra learning approaches. It encourages team work, while the overall learning effect was moderately enlarged. Wongso et al. (2014) proposed a conceptual framework design, based on Web 2.0 technology and gamification. They offered a guideline for implementing gamification and Web 2.0 technology in e-learning systems. Their framework includes the phases of analysis, design, development, implementation and evaluation. Garcia et al. (2017) have offered a framework for gamification in software engineering. This framework is composed of the ontology, a methodology for guiding the process and a support gamification engine. In a case study a company used the framework to gamify the areas of project management, requirements, management and testing. Urh et al. (2015) have provided a model for gamification of e-learning systems. They have included previously listed development phases with management of e-learning, important factors for e-learning, game mechanics, game dynamics, gamification elements and their effects on students. Authors have found several important factors like pedagogy, technology, design, administration, people, learning materials and finance. The goals of their model were to maximize student satisfaction, motivation, effectiveness and efficiency. Song et al. (2017) have investigated the impact of gamification on engagement of college students in class. The results indicated that gamified approaches could be effective in engaging students that are bashful or distracted.

On the other hand, Glover has presented some criticism of gamification (Glover, 2013). At first, the educational experience should be rewarding by itself and only after that, gamification can make it more rewarding. Glover found that learners with high intrinsic motivation can be demotivated by some additional motivation. Therefore, gamification elements in e-learning should be carefully designed and optional for users. Also, gamification could discourage some of the less competitive learners. Author has suggested some questions to find out if the gamified approach is appropriate in a given situation, like: Is motivation really a problem, are there behaviors to encourage, can an activity be gamified, would it favor some learners, what rewards would provide the most motivation, are rewards too easy to obtain? Author concludes that gamification depends a lot on quality materials, activities and experiences, but it can provide additional motivation with careful consideration of its implementation.

Schreuders and Butterfield explored ways to increase student involvement in the teaching process and increase motivation and to enhance students' experience in passing through the educational process. Their study lasted for two years and included 32 students. The results of the research showed positive indicators in terms of qualitative and quantitative results in knowledge tests. Authors conclude that their research, regardless of the small number of participants, is in line with other studies that speak of the positive effects of gamification on increasing motivation and the improvement of the students' experience in using the e-learning system (Schreuders and Butterfield, 2016).

Iosup and Epema created two e-courses that were conducted over four semesters with over 450 students. They see gamification as a set of tools that can influence the motivation and behavior of users. The result of their analysis is that more than $75 \%$ of students had passed the knowledge check on the first exam period. There was also a positive correlation between students who passed the knowledge test and satisfaction test that is attributed to gamified elements (Iosup and Epema, 2014).

De-Marcos et al. (2014) developed a gamified add-on for the BlackBoard LMS system that has enabled tracking of teaching activities to a total of 371 students, as well as mutual co-operation and mutual competition. The ecourse was open to students for one semester. The authors noted a problem where experimental groups showed very little interest in teaching materials. Approximately $20 \%$ of the students actively participated 
in the research, which makes are wonder if the research could have been better designed. It is suggested that repeating this research with focusing on the social component instead of the achievements, badges and competition could be helpful (De-Marcos et al., 2014).

In the present times, authors like Khandelwal et al. (2017; Kosurkar et al., 2017; Llanos et al., 2016) and others have researched influence of gamification on the programing educational fields through the use of specialized software tools and add-ons. Although those examples are of high value to the research subject, the problem remains and that is that the use of e-courses lies on the back of Moodle platform. We think that the Moodle should get higher approach from the researches over the Globe and that all together create unified and standardized set of gamified elements for next generation of students in every University based lectures.

Generally, we can note that other authors such as Schreuders and Butterfield (2016; Iosup and Epem, 2014; de-Marcos et al., 2014) carried out similar experiments. The duration of these experiments was longer, while the number of used gamified elements was smaller compared to our research. In total, all of these studies lead to similar results.

\section{Research Plan}

The research was conducted in two Croatian higher education institutions and it included both full-time and part-time students. The pre-research included students who enrolled in the course $3 D$ modeling on University North and the main research included students who enrolled in the course Programming 2 on Faculty of Organization and Informatics, University of Zagreb. In accordance with the obligations stipulated within each course, students were not overburdened with additional attendance at the faculty, outside their regular classes. Participation in the research was voluntary, but despite that fact, almost all students agreed to participate in the research.

Students were divided into experimental and control groups. In order to keep the interaction between groups to a minimum, the planned timeframe for the research was 20-25 working days. The research goals were presented to the students during this period. Next, in order to determine students' current level of knowledge, a pre-test was conducted. Also, based on the results of the pre-test, we examined the difference in knowledge between all groups of participants.

Students' were rewarded with additional points in the $3 D$ modeling and the Programming 2 courses. Within the $3 D$ modeling course, students had the opportunity to win additional 3 points. Students who participated in the complete research received 3 points, students who participated partially (participated in the pre-test, but not in other activities) received 1 point and students who did not participate at all did not receive any additional points. Within the Programming 2 course, $25 \%$ of the best-performing students in the experimental and control group received 4 points. The next $25 \%$ of the students of both groups received 3 points. Again, the next $25 \%$ of the students of both groups received 2 points and finally, the last group of students, who had the lowest scores, got 1 point.

Students had a minimum of two weeks for the usage of teaching materials from a gamified and an unmodified e-course. In the following week, after using the teaching materials, a post-test was performed. The goal of the post-test was to determine the difference in knowledge, compared to the pre-test results and after using different teaching materials.

\section{Gamified Design Elements}

In the unmodified e-course students were able to access digital teaching content that were presented through text, photography and video. Students had the default look and feel of the Moodle system at their disposal (without any embellishment or removal of elements) Students could use forum for communication purposes, but no other gamified element were included in the system. The classical e-course does not have a reward system or the ability to look at other students' points/performance. It does not have the ability to conducts assessments and tests or provide any automated feedback. An integral part of the classical e-course are options like New Announcement, Future Events, Recent The control group had access to e-course Activity as well as Navigation and Basic System Settings.

The control group had access to e-course filled with a couple of gamified elements, such as: Avatars, forum based communication and non-linear access to teaching materials. In the gamified e-course students had the same ability to access digital teaching content through text, photography and video. The main difference is that they also have at their disposal all the gamified elements listed in Table 1. The look of the gamified e-course is shown in the Fig. 1.

\section{Participants and Groups}

Participants of the pre-research were second year students of University North who attended the elective course $3 D$ modeling and volunteered to participate. The total number of participants was 55, of which $33 \%$ were full-time and $67 \%$ part-time students. Participants were divided into four groups with 15 students in each group. $44 \%$ of participants were female and $56 \%$ male. The average age of participants in this research was 20. A graphical representation of pre-research participants' statuses in displayed in Fig. 2.

For the pre-research purposes the following groups of participants were paired: 
- $\quad \mathbf{G 1}$ and G2, $\mathbf{N}_{\mathbf{G 1}}=15 ; \mathbf{N}_{\mathbf{G} 2}=13 ; \mathbf{M}_{\mathbf{G 1}}=14,53 ; \mathbf{M}_{\mathbf{G} 2}$ $=13,31 ; \mathbf{t}=0,79 ; \mathbf{p}=0,4318$

- $\quad \mathbf{G 4}$ and G3, $\mathbf{N}_{\mathbf{G} 4}=13 ; \mathbf{N}_{\mathbf{G} 3}=14 ; \mathbf{M}_{\mathbf{G} 4}=17,69 ; \mathbf{M}_{\mathbf{G} 3}$ $=17,29 ; \mathbf{t}=0,20 ; \mathbf{p}=0,8374$

where, G1 and G4 are experimental groups and G2 and G3 are control groups.

Participants of the main research were students of Faculty of Organization and Informatics, University of Zagreb who attended the course Programming 2 undergraduate study of information science in the winter semester of the academic year 2015/2016. The total number of participants who volunteered for the research was 201. Participants were divided into 14 groups of 15 students. 44 students or $21.89 \%$ were female and 157 students or $78.11 \%$ were male. The average age of participants was 20. A graphical representation of main research participants' statuses in displayed in Fig. 3.

Table 1: Mechanics and aesthetics in the gamification system (Nielson (2013; Schonfeld, 2010))

\begin{tabular}{llll}
\hline Achievements & Bonuses & Countdown & Endless duration of the game \\
\hline Duties/Challenges & Introduction with the information & Uncertainty/Detection & Levels \\
$\begin{array}{l}\text { Behavioural momentum } \\
\text { Productivity }\end{array}$ & "Combo" effect×3 & Epic meaning & Loss of aversion \\
$\begin{array}{l}\text { Ownership } \\
\text { Points }\end{array}$ & Joint collaboration & Surprise & Conscious risk \\
& Regular rewarding & Advancement & Optimism \\
& Status & Tasks and challenges & "Addiction"/Commitment \\
& & & to the game \\
\hline
\end{tabular}

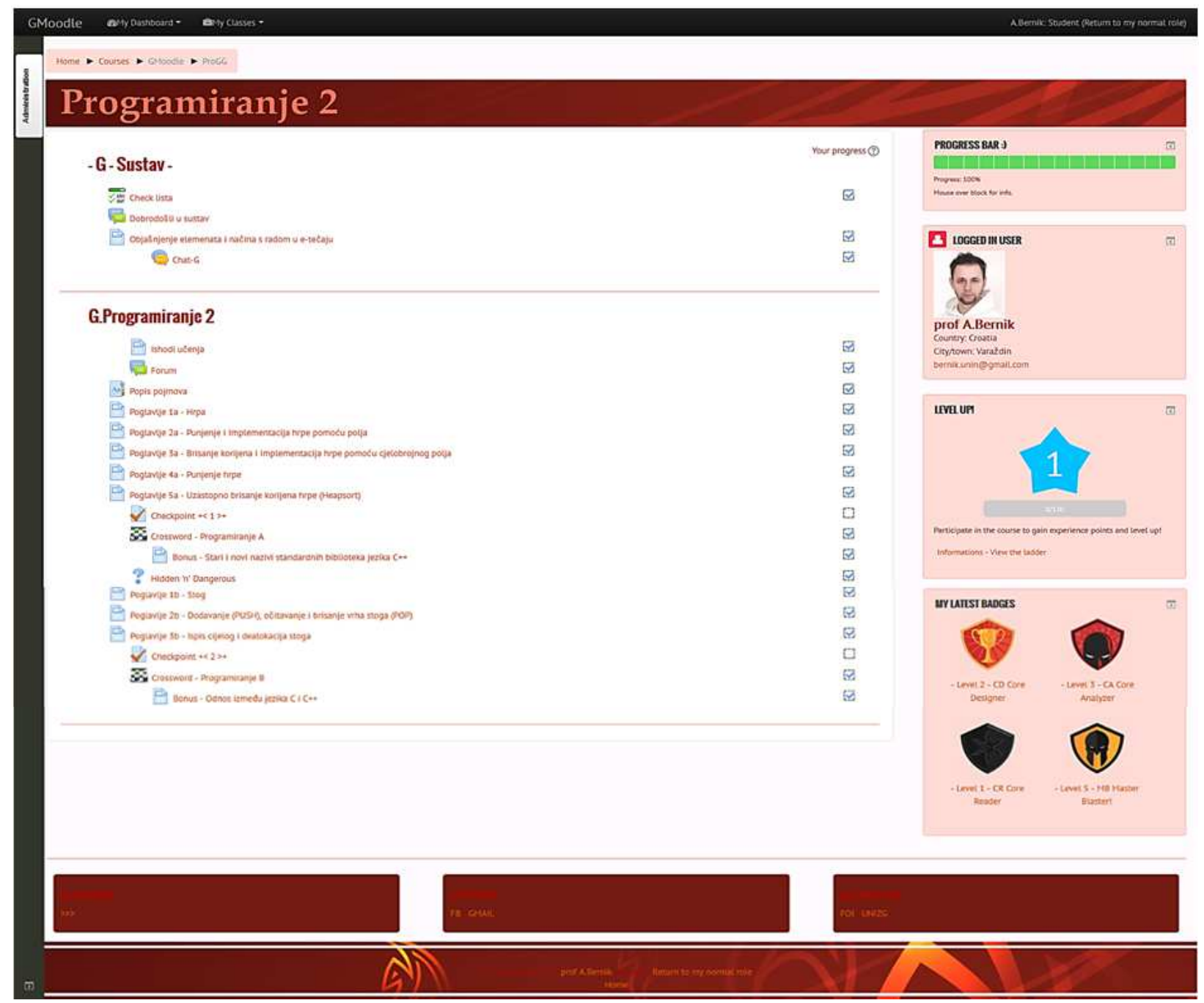

Fig. 1: Gamified e-course 


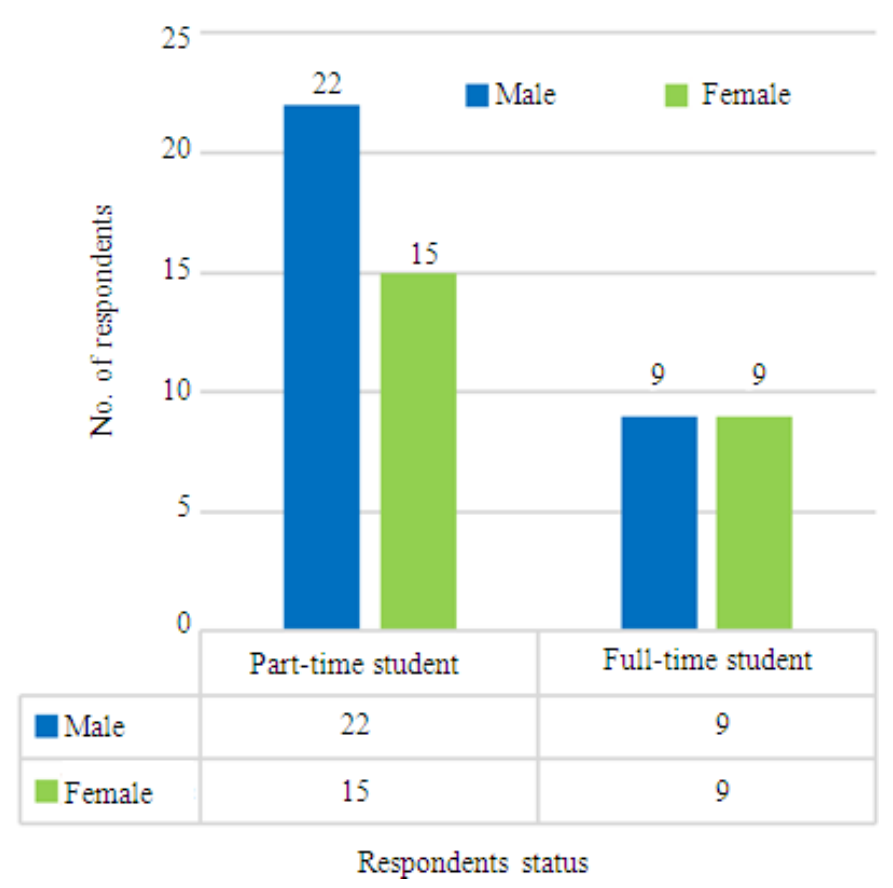

Fig. 2: Pre-research participants' status graph

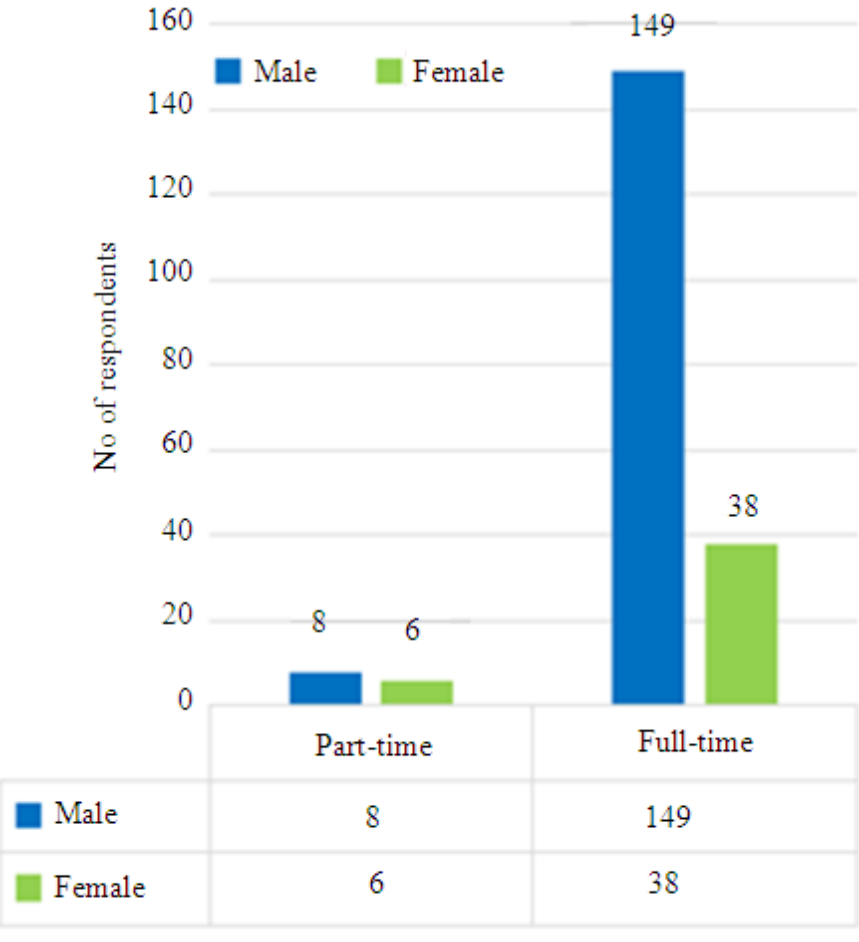

Respondents status

Fig. 3: Main research participants' status graph

For the main research purposes the following groups of participants were paired:

- $\quad \mathbf{G} 2$ and $\mathrm{G} 8, \mathbf{N}_{\mathbf{G} 2}=15 ; \mathbf{N}_{\mathbf{G} 8}=15 ; \mathbf{M}_{\mathbf{G} 2}=15,60 ; \mathbf{M}_{\mathbf{G} 8}$ $=14,93 ; \mathbf{t}=0,41 ; \mathbf{p}=0,6826$
- $\quad \mathbf{G 3}$ and G9, $\mathbf{N}_{\mathbf{G} 3}=14 ; \mathbf{N}_{\mathbf{G} 9}=15 ; \mathbf{M}_{\mathbf{G 3}}=17,29 ; \mathbf{M}_{\mathbf{G 9}}$ $=14,60 ; \mathbf{t}=1,96 ; \mathbf{p}=0,0595$

- $\quad \mathbf{G 5}$ and $\mathrm{G} 13, \mathbf{N}_{\mathbf{G 5}}=15 ; \mathbf{N}_{\mathbf{G 1 3}}=14 ; \mathbf{M}_{\mathbf{G 5}}=15,00$; $\mathbf{M}_{\mathbf{G 1 3}}=15,64 ; \mathbf{t}=0,46 ; \mathbf{p}=0,6481$ 
- $\quad \mathbf{G} 7$ and $\mathrm{G} 4, \mathbf{N}_{\mathbf{G 7}}=13 ; \mathbf{N}_{\mathbf{G} 4}=14 ; \mathbf{M}_{\mathbf{G 7}}=14,92 ; \mathbf{M}_{\mathbf{G} 4}$ $=13,36 ; \mathbf{t}=1,12 ; \mathbf{p}=0,2724$

- $\quad \mathbf{G 1 1}$ and G10, $\mathbf{N}_{\mathbf{G 1 1}}=13 ; \mathbf{N}_{\mathbf{G 1 0}}=15 ; \mathbf{M}_{\mathbf{G 1 1}}=14,31 ;$ $\mathbf{M}_{\mathbf{G 1 0}}=15,33 ; \mathbf{t}=0,82 ; \mathbf{p}=0,4171$

- $\quad \mathbf{G 1 2}$ and G1, $\mathbf{N}_{\mathbf{G 1 2}}=15 ; \mathbf{N}_{\mathbf{G 1}}=15 ; \mathbf{M}_{\mathbf{G 1 2}}=16,00 ;$ $\mathbf{M}_{\mathbf{G 1}}=17,07 ; \mathbf{t}=0,60 ; \mathbf{p}=0,5483$

- $\quad \mathbf{G}_{14}$ and G6, $\mathbf{N}_{\mathbf{G 1 4}}=14 ; \mathbf{N}_{\mathbf{G 6}}=14 ; \mathbf{M}_{\mathbf{G 1 4}}=15,71$; $\mathbf{M}_{\mathbf{G 6}}=15,71 ; \mathbf{t}=0,00 ; \mathbf{p}=1,0000$

where, G2, G3, G5, G7, G11, G12 and G14 are experimental groups and G1, G4, G6, G8, G9, G10 and G13 are control groups.

\section{Hypotheses and Methods}

Aligned with the main goal of this research, to test efficiency of applying gamified design elements in university-level informatics e-courses, we state the following three hypotheses for our research:

H1: The experimental group of participants who achieved a minimum of 50\% score in the pre-test will achieve statistically significant results, compared to the control group of participants who gained a minimum of 50\% score in the pre-test, with respect to the achieved scores in the post-test

H2: Regardless of the participants' gender, $50 \%$ of the highest ranked students in the experimental group will achieve a statistically significant score compared to $50 \%$ of the highest ranked students in the control group

H3: Regardless of the participants' gender, 50\% of the lowest ranked students in the experimental group will achieve a statistically significant score compared to $50 \%$ of the lowest ranked students in the control group

General scientific methods such as observation, description, comparative methods, synthesis methods, analysis and methods for statistical processing of empirically collected data (t-test) were used in order to test the three hypotheses. It is important to emphasize that the hypotheses $\mathrm{H} 2$ and $\mathrm{H} 3$ only refer to the results of the main research (conducted within the Programming 2 course). The pre-research (conducted within the $3 D$ modeling course) did not have a sufficient sample of participants to test these hypotheses.

\section{Results}

\section{Pre-Research Results}

Statistical significance of the pre-research, based on post-test results, is displayed in Table 2. The calculation is based on the comparison of all experimental (G1, G4) groups and all control groups (G2, G3). The average number of points before the experiment was 16.00 for the experimental group and 15.37 the control group. Using the pre-test results, $p$ values were calculated to show that there is no statistically significant difference between the comparison groups. This result is important as it ensues approximately the same initial conditions that need to be achieved before conducting the experiment.

Experimental groups used experimental (gamified) ecourses, while control groups approached classical (unmodified) e-courses. In the first week after the ecourse, a post-test was conducted. The average number of points on the post-test increased by $30.5 \%$ for the experimental group and amounted to 20.89 . The average number of points on the post-test decreased by $0.52 \%$ for the control group and amounted to 15.30 . Intermediate $t$ value after the experiment is 3.99 and the calculated $p$ value is 0.0002 . Based on that, we conclude (with a $1 \%$ possibility of error) that there is a statistically significant difference between experimental and control groups, considering the average post-test results.

For testing the hypothesis $\mathrm{H} 1$, additional results analysis was performed only for participants who have met the condition of achieving a minimum of $50 \%$ of the total points in the pre-test. Of the total number of participants, 25 met this requirement. Students who did not meet this requirement were removed from the results, after which the score points were re-analyzed. Table 3 shows the analysis of post-test results for closed-type questions, open type questions and total number of points. It is evident that the average scores in all three cases are higher for the experimental group. Standard deviation is higher for the control group only in the case of open type questions. The calculated $p$ value shows that in the case with open type questions there is a marginal statistically significant difference, which can be attributed to a small number of participants in the preresearch. In the other two cases, with closed type questions and total score analysis, the calculated $p$ value shows that the experimental group achieved a better result compared to the control group, with a statistically significant difference. T-test analysis was performed on the overall score. The calculated $t$ value is 3.26 , while the $p$ value is 0.003 . Based on that, we concluded that there is a statistically significant difference in the benefit of the experimental group. The average number of points in the post-test for the experimental group was $40.61 \%$ higher than the average number of points for the control group. Given the overall score on the post-test, where the results are shown only for those participants who achieved at least $50 \%$ of that score on the pre-test, we conclude that the hypothesis $\mathrm{H} 1$ of this research is confirmed. 
Table 2: Pre-research statistical significance of the difference between the pre-test and post-test results

\begin{tabular}{lllllll}
\hline \multirow{2}{*}{ Test } & Participants & $\begin{array}{l}\text { Number of } \\
\text { participants }\end{array}$ & $\begin{array}{l}\text { Average } \\
\text { points }\end{array}$ & $\begin{array}{l}\text { Standard } \\
\text { deviation }\end{array}$ & t value & p value \\
\hline Pre-test & G1, G4 & 28 & 16,00 & 5,19 & 0,48 & 0,6328 \\
& G2, G3 & 27 & 15,37 & 4,48 & & $\mathbf{3 , 9 9}$ \\
Post-test & G1, G4 & 28 & 20,89 & 5,78 & $\mathbf{0 , 0 0 0 2}$ \\
& G2, G3 & 27 & 15,30 & 4,50 & & \\
\hline
\end{tabular}

Table 3: Pre-research comparative analysis of post-test responses for control and experimental groups

\begin{tabular}{|c|c|c|c|c|c|c|}
\hline \multirow{2}{*}{$\begin{array}{l}\text { Participants group } \\
\text { (GE - all experimental } \\
\text { groups, GC - all } \\
\text { control groups) }\end{array}$} & \multicolumn{2}{|c|}{$\begin{array}{l}\text { Closed type questions } \\
\text { (total number of } \\
\text { Questions }=26 \text { ) }\end{array}$} & \multicolumn{2}{|c|}{$\begin{array}{l}\text { Opened type questions } \\
\text { (total number of } \\
\text { questions }=6 \text { ) }\end{array}$} & \multicolumn{2}{|c|}{$\begin{array}{l}\text { Overall score } \\
\text { (total number of } \\
\text { questions }=32 \text { ) }\end{array}$} \\
\hline & $\mathbf{G}_{\mathbf{E}}$ & $\mathrm{G}_{\mathrm{C}}$ & $\mathbf{G}_{\mathbf{E}}$ & $\mathrm{G}_{\mathrm{C}}$ & $\mathbf{G}_{\mathbf{E}}$ & $\mathrm{G}_{\mathrm{C}}$ \\
\hline Average points & 19,42 & 14,15 & 4,17 & 2,62 & 23,58 & 16,77 \\
\hline Standard deviation & 3,80 & 3,16 & 1,75 & 2,02 & 5,42 & 5,04 \\
\hline Number of participants & 12 & 13 & 12 & 13 & 12 & 13 \\
\hline t value & 3,77 & & 2,04 & & 3,26 & \\
\hline $\mathrm{p}$ value & $\mathbf{0 , 0 0 1}$ & & $\mathbf{0 , 0 5 2}$ & & $\mathbf{0 , 0 0 3}$ & \\
\hline
\end{tabular}

\section{Main Research Results}

Statistical significance of the main research, based on post-test results, is displayed in Table 4 . The calculation is based on the comparison of all experimental (G2, G3, G5, G7, G11, G12, G14) and all control groups (G1, G4, G6, G8, G9, G10, G13). The average number of points before the experiment was 15.54 for the experimental group and 15.23 for the control group. The experimental group achieved better results by $2.03 \%$. Using the pretest results, $p$ values were calculated to show that there is no statistically significant difference between the comparison groups. Experimental groups used experimental (gamified) ecourses, while control groups approached classical (unmodified) e-courses. In the first week after the ecourse, a post-test was conducted. The average number of points after the experiment decreased by $11.87 \%$ for the experimental group and amounted to 13.89 points. For the control group it decreased by $26.60 \%$ and amounted to 12.03 points. Intermediate value $\mathrm{t}$ after the experiment is 2.68 and the calculated $\mathrm{p}$ value is 0.007 . Based on that, we conclude (with a $1 \%$ possibility of error) that there is a statistically significant difference between experimental and control groups, considering the average post-test results.

For testing the hypothesis $\mathrm{H} 1$, additional results analysis was performed only for participants who have met the condition of achieving a minimum of $50 \%$ of the total points in the pre-test. Of the total number of participants, 118 of them met this requirement. Students who did meet this requirement were removed from the results, after which the score points were re-analyzed. Table 5 shows the analysis of post-test results for closedtype questions, open type questions and total points. The average score is higher, as is the standard deviation, for the experimental group in all three cases.
The calculated $\mathrm{p}$ value shows that in the case with closed type questions there is no statistically significant difference, although it is marginal. In the other two cases, with open type questions and total score analysis, the calculated $p$ value shows that the experimental group achieved better results with a statistically significant difference. All experimental groups had higher average score than all control groups, based on the total number of points that the students achieved on the post-test. The points were summed up and t-test was performed. The calculated $t$ value is 2.53 and the $p$ value is 0.0127 . Based on that we conclude that there is a statistically significant difference between the experimental and control groups. The average post-test score in the experimental group was $21.67 \%$ higher than the average post-test score in the control group. Given the overall score on the post-test, where the results are shown only for those participants who achieved at least $50 \%$ of that score on the pre-test, the main research also confirms hypothesis H1.

In order to test hypothesis $\mathrm{H} 2$ and $\mathrm{H} 3$, the participants in the control and experimental groups were additionally divided to $50 \%$ highest ranked and $50 \%$ lowest ranked, based on their pre-test results. Table 6 displays the comparison of $50 \%$ highest ranked participants in the experimental group with $50 \%$ of the highest ranked participants in the control group, as well as $50 \%$ of the lowest ranked participants in the experimental group with $50 \%$ of the lowest ranked participants in the control group. There is a statistically significant difference between the post-test score of the $50 \%$ highest ranked participants. The calculated $t$ value is 2,578, while the $\mathrm{p}$ value is 0,011 . Experimental group of participants achieved a $21.93 \%$ better score then the control group. Based on that results, we conclude that hypothesis $\mathrm{H} 2$ of this research is confirmed. 
Table 4: Main research statistical significance of the difference between the pre-test and post-test results

\begin{tabular}{|c|c|c|c|c|c|c|}
\hline Test & $\begin{array}{l}\text { Participants } \\
\text { group (GE - all experimental } \\
\text { groups, GC - all control groups) }\end{array}$ & $\begin{array}{l}\text { Number of } \\
\text { participants }\end{array}$ & $\begin{array}{l}\text { Average } \\
\text { points }\end{array}$ & $\begin{array}{l}\text { Standard } \\
\text { deviation }\end{array}$ & $\mathrm{t}$ value & $\mathrm{p}$ value \\
\hline & $\mathrm{G}_{\mathrm{E}}$ & 99 & 15,5 & 4,17 & 0,57 & 0,5658 \\
\hline \multirow[t]{2}{*}{ Pre-test } & $\mathrm{G}_{\mathrm{C}}$ & 102 & 15,25 & 3,72 & & \\
\hline & $\mathrm{G}_{\mathrm{E}}$ & 96 & 13,89 & 5,42 & 2,68 & 0,0079 \\
\hline Post-test & $\mathrm{G}_{\mathrm{C}}$ & 96 & 12,03 & 4,05 & & \\
\hline
\end{tabular}

Table 5: Main research comparative analysis of post-test responses for control and experimental groups

\begin{tabular}{|c|c|c|c|c|c|c|}
\hline \multirow{2}{*}{$\begin{array}{l}\text { Participants group } \\
\text { (GE - all experimental } \\
\text { groups, GC - all } \\
\text { control groups) }\end{array}$} & \multicolumn{2}{|c|}{$\begin{array}{l}\text { Closed type questions } \\
\text { (total number of } \\
\text { Questions }=25 \text { ) }\end{array}$} & \multicolumn{2}{|c|}{$\begin{array}{l}\text { Opened type questions } \\
\text { (total number of } \\
\text { questions = 5) }\end{array}$} & \multicolumn{2}{|c|}{$\begin{array}{l}\text { Overall score } \\
\text { (total number of } \\
\text { questions }=30 \text { ) }\end{array}$} \\
\hline & $\mathbf{G}_{\mathbf{E}}$ & $\mathrm{G}_{\mathrm{C}}$ & $\mathbf{G}_{\mathbf{E}}$ & $\mathrm{G}_{\mathrm{C}}$ & $\mathbf{G}_{\mathbf{E}}$ & $\mathrm{G}_{\mathrm{C}}$ \\
\hline Average points & 12,08 & 10,49 & 2,14 & 1,32 & 14,37 & 11,81 \\
\hline Standard deviation & 4,99 & 4,39 & 1,59 & 1,17 & 5,88 & 5,07 \\
\hline Number of participants & 59 & 59 & 59 & 59 & 59 & 59 \\
\hline $\mathrm{t}$ value & 1,84 & & 3,17 & & 2,53 & \\
\hline $\mathrm{p}$ value & 0,068 & & 0,002 & & 0,012 & \\
\hline
\end{tabular}

Table 6: Main research comparative analysis of results for 50\% highest ranked and 50\% lowest ranked participants of experimental and control groups

\begin{tabular}{llll}
\hline & $\begin{array}{l}\text { Overall score } \\
50 \% \text { highest ranked participants }\end{array}$ & \multicolumn{1}{c}{ Overall score } \\
& $-10 \%$ lowest ranked participants & Control \\
Participants group & Experimental & Control & Experimental \\
\hline Average points & 14,40 & 11,81 & 12,03 \\
Standard deviation & 5,84 & 5,07 & 5,63 \\
Number of participants & 60 & 59 & 39,65 \\
t value & 2,578 & & 1,226 \\
p value & 0,011 & & 0,223 \\
\hline
\end{tabular}

In the analysis of $50 \%$ of the lowest ranked participants, the calculated t value is 1.226 , while the $\mathrm{p}$ value is 0.223 . The statistically significant difference, in this case, does not exist, despite the higher average scores recorded in the experimental group. Experimental group achieved a $12.96 \%$ better score then the control group in the post-test. We conclude that there is no statistically significant difference between the control and experimental groups, in the analysis of $50 \%$ of the lowest ranked participants and thus we reject the hypothesis $\mathrm{H} 3$ of this research.

\section{Conclusion}

In this research we had total of 256 participants who were tested on three hypotheses. $\mathrm{H} 1$ and $\mathrm{H} 2$ were expected, but H3 was surprise. This finding could have serious impact on future researches if the participants have lower knowledge. Based on the average number of points on the post-test, where we analyzed only the results of participants who achieved at least $50 \%$ of the total score on the pre-test, we confirmed the hypothesis H1. Similarly, we analyzed the results of participants with the highest ranking and confirmed the hypothesis $\mathrm{H} 2$. In our analysis of the results for participants with the lowest ranking we found no statistically significant difference and thus rejected hypothesis $\mathrm{H} 3$. This means that students from control group with lower knowledge didn't had statistical different test results from the experimental group students. Gamification didn't influence those two group which is interesting and definitely something that needs more exploration in the future.

The research extends our earlier results (published at international conferences CECIIS and MIPRO) where the positive impact of a gamified e-courses on the student's knowledge was measured. This research shows that there is an even greater outcome in the results if only the highest rated students from the control group are compared to the highest rated students from experimental group.

There are still some remaining challenges and open questions in this field. One of the biggest challenges is creating a standardized solution that would be universal for all Moodle e-courses in the IT field as well as in any other field. Open questions we will try to answer in our future work include: When an e-course starts to be a gamified one and when it stops; and what are the best elements from computer games to be applied in higher education e-learning. 


\section{Acknowledgements}

The authors wish to thank University North as well as Faculty of Organization and Informatics in Varaždin for allowing the conduction of this research. Authors are also grateful to the reviewers for their valuable comments.

\section{Author's Contributions}

Andrija Bernik: The main responsible author for research design, design of gamified e-courses and implementation of pre-research. Contributed in planning, design, writing, data collection and analysis of the results.

Danijel Radošević: The main responsible author for implementation of the main research. Contributed in design, planning, data collection and analysis of the results.

Daniel Strmečki: The main responsible author for literature review and writing. Contributed in literature review, writing, translation and analysis of the results.

\section{Ethics}

This article is original and contains unpublished material. The corresponding author confirms that all of the other authors have read and approved the manuscript and no ethical issues involved.

\section{References}

Bernik, A., D. Radošević and G. Bubaš, 2017. Introducing gamification into e-learning university courses. Proceedings of the 40th International Convention on Information and Communication Technology, Electronics and Microelectronics, May 22-26, IEEE Xplore Press, Opatija, Croatia, pp: 22-26, DOI: 10.23919/MIPRO.2017.7973515

Bernik, A., G. Bubaš and D. Radošević, 2015. A pilot study of the influence of gamification on the effectiveness of an e-learning course. Proceedings of the 26th Central European Conference on Information and Intelligent Systems, (IIS' 15), Varazdin, Croatia, pp: 73-79.

De-Marcos, L., A. Domínguez, J. Saenz-de-Navarrete and C. Pagés, 2014. An empirical study comparing gamification and social networking on e-learning. Comput. Educ., 75: 82-91.

DOI: 10.1016/j.compedu.2014.01.012

Deterding, S., D. Dixon, R. Khaled and L. Nacke, 2011. From game design elements to gamefulness: Defining "gamification". Proceedings of the 15th International Academic MindTrek Conference: Envisioning Future Media Environments, Sep. 28-30, ACM, Tampere, Finland, pp: 3-4.

DOI: $10.1145 / 2181037.2181040$

Domínguez, A., J. Saenz-de-Navarrete, L. de-Marcos, L. Fernández-Sanz and C. Pagés et al., 2013. Gamifying learning experiences, practical implications and outcomes. Comput. Educ., 63: 380-392.

DOI: $10.1016 /$ j.compedu.2012.12.020
Enders, B., 2013. Gamification, games and learning: What managers and practitioners need to know. The E-learning Guild.

Garcia, F., O. Pedreira, M. Piattini, A. Cerdeira-Pena and M. Penabad, 2017. A framework for gamification in software engineering. J. Syst. Software, 132: 21-40. DOI: $10.1016 /$ j.jss.2017.06.021

Glover, I., 2013. Play as you learn: Gamification as a technique for motivating learners. Proceedings of World Conference on Educational Multimedia, Hypermedia and Telecommunications, (MHT' 13), Chesapeake, VA, AACE, pp: 1999-2008. DOI: $10.1145 / 1979742.1979575$

Hamari, J., J. Koivisto and H. Sarsa, 2014. Does gamification work? -- A literature review of empirical studies on gamification. Proceedings of the 47th Hawaii International Conference on System Sciences, Jan. 6-9, IEEE Xplore Press, Washington, pp: 3025-3034. DOI: 10.1109/HICSS.2014.377

Hof, S., M. Kropp and M. Landolt, 2017. Use of gamification to teach agile values and collaboration: A multi-week scrum simulation project in an undergraduate software engineering course. Proceedings of the Conference on Innovation and Technology in Computer Science Education, Jul. 03-05, ACM, Bologna, Italy, pp: 323-328. DOI: $10.1145 / 3059009.3059043$

Huotari, K. and J. Hamari, 2012. Defining gamification: A service marketing perspective. Proceedings of the 16th International Academic Mindtrek Conference, (AMC'12), ACM, Tampere, Finland, pp: 17-22. DOI: $10.1145 / 2393132.2393137$

Iosup, A. and D. Epema, 2014. An experience report on using gamification in technical higher education. Proceedings of the 45th Technical Symposium on Computer Science Education Atlanta, Mar. 05-08, ACM, Georgia, pp: 27-32. DOI: $10.1145 / 2538862.2538899$

Kapp, K.M., 2012. The Gamification of Learning and Instruction: Game-Based Methods and Strategies for Training and Education. 1st Edn., John Wiley and Sons, San Francisco, CA, ISBN-10: 1118096347 , pp: 302.

Khandelwal, S., S. Sripada and Y.R. Reddy, 2017. Impact of gamification on code review process: An experimental Study. Proceedings of the 10th Innovations in Software Engineering Conference, Feb. 5-7, ACM, Jaipur, India, pp: 122-126. DOI: $10.1145 / 3021460.3021474$

Kosurkar, V., A. Zade, A. Tikas, S. Prasad and B. Sure et al., 2017. Learning programming language with game-like elements integrated on a web-based platform and assessment using formative feedback. Int. J. Eng. Sci. Nagpur, India, 7: 5268- 5271. DOI: $10.1017 / \mathrm{CBO} 9780511816819.006$ 
Llanos, D.R., J. Fresno H. Ortega-Arranz, A. OrtegaArranz and A. Gonzalez-Escribano et al., 2016. Applying Gamification in a Parallel Programming Course. In: Gamification-Based E-Learning Strategies for Computer Programming Education, de Queirós, R.A.P. and M.T. Pinto (Eds.), IGI Global, ISBN-10: 1522510346, pp: 350-350.

Nielson, B., 2013. Gamification Mechanics vs. Gamification Dynamics. 1st Edn., Your Training Edge.

Schonfeld, E., 2010. SCVNGR's secret game mechanics playdeck. Oath Tech Network, United States.

Schreuders, Z.C. and E. Butterfield, 2016. Gamification for teaching and learning computer security in higher education. Proceedings of the USENIX Workshop on Advances in Security Education, (ASE’ 16), Austin, Texas.

Song, D., P. Ju and H. Xu, 2017. Engaged cohorts: Can gamification engage all college students in class? Eurasia J. Math. Sci. Technol. Educ., 13: 3723-3734.

Urh, M., G. Vukovic, E. Jereb and R. Pintar, 2015. The model for introduction of gamification into elearning in higher education. Procedia Soc. Behavioral Sci., 197: 388-397.

DOI: $10.1016 /$ j.sbspro.2015.07.154
Wongso, O., Y. Rosmansyah and Y. Bandung, 2014. Gamification framework model, based on social engagement in e-learning 2.0. Proceedings of the 2nd International Conference on Technology, Informatics, Management, Engineering and Environment, Aug. 19-21, IEEE Xplore Press, Bandung, Indonesia.

DOI: 10.1109/TIME-E.2014.7011583

Zichermann, G. and C. Cunningham, 2011. Gamification by Design: Implementing Game Mechanics in Web and Mobile Apps. "O'Reilly Media, Inc., Cambridge, ISBN-10: 1449315399, pp: 208. 